\title{
Chronic Heat Stress Weakened the Innate Immunity and Increased the Virulence of Highly Pathogenic Avian Influenza Virus H5N1 in Mice
}

\author{
Yi Jin, Yanxin Hu, Deping Han, and Ming Wang \\ Key Laboratory of Zoonosis of Ministry of Agriculture, College of Veterinary Medicine, China Agricultural University, \\ Beijing 100193, China \\ Correspondence should be addressed to Ming Wang, vetdean@cau.edu.cn
}

Received 19 October 2010; Revised 14 March 2011; Accepted 1 April 2011

Academic Editor: Frederick D. Quinn

Copyright () 2011 Yi Jin et al. This is an open access article distributed under the Creative Commons Attribution License, which permits unrestricted use, distribution, and reproduction in any medium, provided the original work is properly cited.

Chronic heat stress (CHS) can negatively affect immune response in animals. In this study we assessed the effects of CHS on host innate immunity and avian influenza virus H5N1 infection in mice. Mice were divided into two groups: CHS and thermally neutral (TN). The CHS treatment group exhibited reduced local immunity in the respiratory tract, including the number of pulmonary alveolar macrophages and lesions in the nasal mucosa, trachea, and lungs. Meanwhile, CHS retarded dendritic cells (DCs) maturation and reduced the mRNA levels of IL-6 and IFN- $\beta$ significantly $(P<.05)$. After the CHS treatment, mice were infected with $\mathrm{H} 5 \mathrm{~N} 1$ virus. The mortality rate and viral load in the lungs of CHS group were higher than those of TN group. The results suggest that the CHS treatment could suppress local immunity in the respiratory tract and innate host immunity in mice significantly and moderately increased the virulence in $\mathrm{H} 5 \mathrm{~N} 1$-infected mice.

\section{Introduction}

Heat stress can negatively affect an animal's growth performance and the immune competence to some bacterial or viral infection [1-6]. It has been reported that heat stress results in decease of weights of both primary and secondary lymphoid organs, profiles of circulating leukocytes, $\mathrm{T}$ cell in the blood, and antibody response to sheep red blood cells (SRBCs) or against Newcastle disease [710]. Our previous studies have demonstrated that chronic heat stress condition negatively affects both humoral and cellular responses against foot and mouth disease virus (FMDV) in mice [2]. However, there have been few detailed studies addressing the effects of CHS on the innate immune response as the most immediate defense against viral infection.

The H5N1 subtype of highly pathogenic avian influenza viruses (HPAIVs) causes infections in domestic poultry and humans. It is epidemiologically characterized by wide dissemination and rapid prevalence and is a threat to public health. So far human cases of H5N1 infection in worldwide have increased to 522, including 309 deaths (http:// www.who.int/csr/disease/avian_influenza/country/cases_table _2011_02_25/en/index.html). The data from WHO demonstrated that most human cases of $\mathrm{H} 5 \mathrm{~N} 1$ infection occurred in the tropical and subtropical countries, such as Egypt, Vietnam, and Indonesia, instead of the high latitude countries. (http:/www.who.int/csr/disease/avian_influenza/country/cas es_table_2011_02_25/en/index.html). In mainland China, the outbreak of $\mathrm{H} 5 \mathrm{~N} 1$ virus in poultry and human cases mainly occurred in the south of the Yangtze associated with high humidity and temperature, including Guangdong, Guangxi and, Fujian province [11]. It is speculative that high temperature may be associated with human or poultry higher susceptibility to $\mathrm{H} 5 \mathrm{~N} 1$ virus. It was also reported that the vast temperature changes frequently occurred one week before the avian influenza outbreak in China [12]. Even in winter, heat stress often occurred under conditions of crowding, heating, and without ventilation in poultry. When those flocks are exposed to $\mathrm{H} 5 \mathrm{~N} 1$ virus, the outbreaks 
of avian influenza may occur. In this study, we measured the effects of CHS on innate host immunity by detecting local immunity in the respiratory tract, maturation or activation of DCs, and cytokine levels in spleens of the mice under CHS or TN conditions. Then we examined mortality rate, histopathology, and viral loads in lung of CHS mice challenged with $\mathrm{H} 5 \mathrm{~N} 1$ virus. We demonstrated that heat stress could increase the susceptibility of animals to the highly pathogenic avian influenza virus (HPAIV) H5N1.

\section{Materials and Methods}

2.1. Virus. The $\mathrm{H} 5 \mathrm{~N} 1$ influenza virus (A/Chicken/Henan/ $1 / 04$ ) used in this study was isolated from infected chicken flocks. This isolate was highly pathogenic on poultry, mouse, and Madin-Darby canine kidney (MDCK) cells. The virus has been adapted in MDCK cells for convenience and propagated in cell culture at $37^{\circ} \mathrm{C}$ for 48 hours. The viral supernatant was harvested, aliquoted, and stored at $-80^{\circ} \mathrm{C}$. The viral titers were determined by plaque assay as described previously [13].

2.2. Animals. Female BALB/c mice that were 8-10-weeksold were obtained from Vital River Laboratories (Beijing, China), while the original breeding pairs were purchased from Charles River (Beijing, China). Mice were raised in independent ventilated cages and received pathogen-free food and water. Experimentation with animals was governed by the Regulations of Experimental Animals of Beijing Authority and approved by the Animal Ethics Committee of the China Agriculture University.

2.3. Chronic Heat Stress Model. Mice were randomly divided into two groups: CHS and TN. Mice in the CHS group were placed in a biological oxygen demand (BOD) incubator for 21 days and subjected to chronic heat exposure for $4 \mathrm{~h}$ at a temperature of $38 \pm 1^{\circ} \mathrm{C}$, simulating high Summer temperatures [14]. Mice in the $\mathrm{TN}$ and control groups were kept in an incubator at $24 \pm 1{ }^{\circ} \mathrm{C}$ to simulate room temperature. Mice were sacrificed at various time-points and the lung and spleen from each mouse were collected.

2.4. Viral Challenge and Sample Collection. The virus stocks were diluted in phosphate-buffered saline (PBS). Mice were anesthetized with Zotile (Virbac, France) intramuscular at a dose of $15 \mathrm{mg} / \mathrm{kg}$ (body weight) and were then infected intranasally with 50 plaque forming units (PFUs) of H5N1 virus. Mice were sacrificed at various time-points and the lung and spleen from each mouse were collected and stored in liquid nitrogen until required.

2.5. Plaque Assay. MDCK cells were cultured in Dulbecco's modified Eagle's medium (DMEM; Hyclone Laboratories) containing 10\% FBS (Hyclone Laboratories), $100 \mathrm{U} / \mathrm{mL}$ penicillin, and $100 \mu \mathrm{g} / \mathrm{mL}$ streptomycin. The supernatants of mouse lung tissues were diluted 10 -fold and added to a monolayer of MDCK cells in semisolid agar that contained
$0.5 \mu \mathrm{g} / \mathrm{mL}$ of trypsin TPCK (Sigma-Aldrich, St Louis, MO, USA). Cultures were incubated at $37^{\circ} \mathrm{C}, 5 \% \mathrm{CO}_{2}$ for $60-72$ hours, fixed, and stained with $1 \%$ crystal violet. The plaques were counted and photographed.

\subsection{Histopathological and Immunohistochemical Analysis.} Tissues were removed and fixed with $4 \%$ neutral formalin at room temperature for $48 \mathrm{~h}$. The serial tissue sections were cut to $5 \mu \mathrm{m}$ thickness after embedding in paraffin. Each slide was stained with hematoxylin and eosin (H\&E) and then examined by light microscopy (Olympus CX31). Examination of influenza viral antigen in the tissue samples was performed by immunohistochemical analysis. Sections were incubated in $10 \%$ normal goat serum in PBS for 30 minutes to block non-specific binding sites before being reacted with the anti-influenza nucleoprotein $\mathrm{mAb}(\mathrm{AA} 5 \mathrm{H}$, Abcam) at $1: 1000$ dilutions in PBS for $2 \mathrm{~h}$. The slides were further incubated with goat anti-mouse IgG conjugated with avidin (Chemicon, USA) for $1 \mathrm{~h}$ and followed by an incubation of the biotinlated peroxidase (Victoria, BC, Canada) for additional $1 \mathrm{~h}$. Staining was visualized by the addition of 3,3-diaminobenzidin (DAB, Sigma, St. Louis, Mo., USA ) for 15 min and counterstained with haematoxylin mounted with neutral balsam.

2.7. Quantitative PCR ( $q P C R$ ). Total RNA was prepared from $10 \mathrm{mg}$ lung tissue homogenized in Trizol (Invitrogen, Carlsbad, CA, USA) according to the manufacturer's instructions. The DNaseI-treated RNA $(0.2 \mu \mathrm{g})$ was reverse transcribed into cDNA. Quantification of expression of the hemagglutinin (HA) gene of $\mathrm{H} 5 \mathrm{~N} 1$ influenza virus was conducted using a Power SYBR Green PCR Master Mix kit (ABI). The following primers were used in the qPCR: forward primer, 5'-CGC AGT ATT CAG AAG AAG CAA GAC-3'; and reverse primer, 5' ${ }^{\prime}$-TCC ATA AGG ATA GAC CAG CTA CCA-3'. The reaction was run on an ABI 7500 thermal cycler with an initial denaturation step at $95^{\circ} \mathrm{C}$ for 10 minutes, followed by 40 cycles of $95^{\circ} \mathrm{C}$ for 15 seconds, $56^{\circ} \mathrm{C}$ for 30 seconds, and $72^{\circ} \mathrm{C}$ for 40 seconds. Data analysis was performed using 7500 software v2.0 (ABI). The copy number of the HA gene was calculated using an HA-containing plasmid of known concentration as a standard.

Quantification by qPCR was performed for five other genes: $\beta$-actin (primers, $5^{\prime}$-GAG ACC TTC AAC ACC CCG C- $3^{\prime}$ and $5^{\prime}$-ATG TCA CGC ACG ATT TCC C-3'), IL-6 (5'AGC CAG AGT CCT TCA- $3^{\prime}$ and $5^{\prime}$-TCT TGG TCC TTA GCC-3'), IL-10 ( $5^{\prime}$-GGT TGC CAA GCC TTA TCG GA-3' and $5^{\prime}$-ACC TGC TCC ACT GCC TTG CT- $\left.3^{\prime}\right)$, IFN- $\beta\left(5^{\prime}-\right.$ TCC AGC TCC AAG AAA GGA CG-3' and $5^{\prime}$-GCA TCT TCT CCG TCA TCT CC- $\left.3^{\prime}\right)$, and HSP70 ( $5^{\prime}$-TGA GCA GCC CAT CCT TAG TG- $3^{\prime}$ and $5^{\prime}$-ATA GGC ATC CGT CCC TTT GT-3'). Reactions were carried out on an ABI 7500 with initial denaturation at $95^{\circ} \mathrm{C}$ for $10 \mathrm{~min}$, then 40 cycles of denaturation at $95^{\circ} \mathrm{C}$ for $15 \mathrm{~s}$, annealing at $50^{\circ} \mathrm{C}$ for $30 \mathrm{~s}$, and extension at $72^{\circ} \mathrm{C}$ for $40 \mathrm{~s}$ using a Power SYBR Green PCR Master Mix kit. Gene expression was normalized to that of the TN group using the $2^{-\Delta \Delta C T}$ method with $\beta$-actin as an internal standard [15]. 
2.8. Bronchoalveolar Lavage (BAL) Collection and Pulmonary Alveolar Macrophage (PAM) Counting. At 21 days after exposure to $38 \pm 1^{\circ} \mathrm{C}$ or $24 \pm 1^{\circ} \mathrm{C}$, the mice were euthanized with a lethal dose of pentobarbital. BAL was collected using $0.8 \mathrm{~mL}$ saline twice from the main stem bronchus. The BAL collected from one mouse was pooled centrifuged, and cells were resuspended in $100 \mathrm{~mL}$ saline containing $0.1 \%$ BSA. Cells were stained with Giemsa, and cell types were identified by morphological criteria. Two hundred cells were examined per slide for the pulmonary alveolar macrophage (PAM) count.

2.9. DC Cell Surface Costimulatory Molecules. Fluorophoreconjugated rat antimouse monoclonal antibodies including anti-MHC-II-PE, anti-CD40-PE, anti-CD80-PE, antiCD86-PE, anti-CD11c-FITC, and isotype controls were purchased from BDPharMingen (San Diego, CA, USA). CFSE was obtained from Molecular Probes (Eugene, OR, USA). Three mice from each group were sacrificed after exposure to $38 \pm 1^{\circ} \mathrm{C}$ or $24 \pm 1^{\circ} \mathrm{C}$ for 21 days, and single cell suspensions from the spleens at a concentration of $2 \times 10^{6}$ cells $/ 200 \mu \mathrm{L}$ were blocked with $2 \mu \mathrm{L} \mathrm{Fc} \gamma$ monoclonal antibody $(0.5 \mu \mathrm{g} / \mathrm{mL})$ for $30 \mathrm{~min}$ at $4^{\circ} \mathrm{C}$. After rinsing once with PBS, cells were stained with isotype controls, or double stained with anti-CD11c-FITC and anti-CD40-PE, or anti-CD11c-FITC and anti-CD80-PE, or anti-CD11c- FITC and anti-CD86-PE, or anti-CD11c-FITC and anti-MHCII-PE. The fluorescent intensities were measured with a FACSCalibur and analyzed with Cell Questpro software (BD Biosciences, USA).

2.10. Statistical Analysis. Statistical analysis was performed using one-way ANOVAs with SPSS 12.0 (SPSS Taiwan Corp., Taiwan) and $P$-values less than .05 were considered statistically significant.

\section{Results}

3.1. Chronic Heat Stress Reduced Local Immunity in the Respiratory Tract of Mice. To determine the effect of CHS on local immunity in the respiratory tract of mice, the histopathological changes in the nasal mucosa, trachea, and lungs of the mice in each group after exposure to $38 \pm 1^{\circ} \mathrm{C}$ or $24 \pm 1^{\circ} \mathrm{C}$ for 21 days were examined (Figure 1(a)). The nasal mucosa lesions of mice in the CHS group exhibited sebaceous gland hyperplasia (Figure 1(A)(b)). The tracheal lesions in the CHS mice were characterized by a reduction in tracheal epithelial cells and many erythrocytes had infiltrated the tube cavity of the trachea (Figure $1(A)(d)$ ). Changes in lung pathology included a reduction and necrosis of mucous epithelium cells in the bronchioles and alveolar expansion (Figure 1(A)(f)). In comparison, the nasal mucosa, trachea, and lungs from the TN group exhibited no apparent histological changes (Figures 1(A)(a), (c), and (e)).

In a previous study, heat stress was characterized by the production of HSPs, especially HSP70 [16]. To determine the mRNA expression of HSP70, we used qPCR analysis. HSP70 expression in the lungs of mice was induced at one day after exposure to $38 \pm 1^{\circ} \mathrm{C}$, peaking at day 5 and then returned to normal levels at day 21 (Figure 1(B)).

The BAL from the mice following exposure to $38 \pm 1^{\circ} \mathrm{C}$ or $24 \pm 1^{\circ} \mathrm{C}$ for 21 days was collected for PAM counting. The number of PAMs in the CHS group were significantly lower than those in the TN group (Figure 1(C)). These results suggest that $\mathrm{CHS}$ can reduce local immunity in the respiratory tract of mice and also inhibit expression of HSP70.

3.2. CHS Weakened the Innate Immunity in Mice. The maturation or activation of DCs is very important for innate immunity and subsequent adaptive immunity. The expression of costimulatory markers CD40, CD86, and CD80 at the DC surface correlated with their capacity to induce or suppress immune responses and the MHC-II expression is important in the initiation of immune response [17]. DC maturation of mice exposed to $38 \pm 1^{\circ} \mathrm{C}$ or $24 \pm 1^{\circ} \mathrm{C}$ for 21 days was determined by FACS (Figures 2(A) and 2(B)). The MHC-II, CD40, CD80 and CD86 expression levels in the CHS group were lower than these of the TN group, especially CD86 and CD40 $(P<.05)$. Previous studies have shown that IL-6, IL-10, and IFN- $\beta$ played critical roles in the innate immune responses [18-20]. To determine the effect of CHS on the innate immunity associated with cytokine expression in mice, the mRNA levels of IL-6, IL-10, and IFN- $\beta$ in the spleen after exposure to $38 \pm 1^{\circ} \mathrm{C}$ or $24 \pm$ $1^{\circ} \mathrm{C}$ were examined. The IL- 6 and IFN- $\beta$ mRNA levels of the CHS group were downregulated significantly compared to the TN group, while IL-10 was significantly upregulated $(P<.05)$ (Figure $2(\mathrm{C}))$. The mRNA level of TNF- $\alpha$ was also measured, but there was no significant difference between two groups (data not shown). These data suggest that CHS could adversely affect the maturation of DCs and innate immunity in mice.

3.3. CHS Increased the Virulence of HPAIV in Infected Mice. To determine whether CHS could impact upon HAPIV $\mathrm{H} 5 \mathrm{~N} 1$ infection, the mice exposed to $38 \pm 1^{\circ} \mathrm{C}$ or $24 \pm 1^{\circ} \mathrm{C}$ for 21 days were challenged with 50 PFU of H5N1 virus. The lung tissues of five mice per group were collected at Day 3 postinfection for real-time PCR, plaque assay, and histopathogic analysis. Six mice per group were observed for mortality rate for 14 days. Results showed that the mice in the CHS group had a higher mortality rate $(67 \%)$ than that in TN group (33\%) (Figure 3(a)), but not statistically significant by log rank analysis possibly due to the small sample size. To examine the viral load in the lung of the mice infected with the virus, $\mathrm{qPCR}$ and plaque assay were performed. Pulmonary viral load in the mice of the CHS group was significantly higher than that of TN group at day 3 postinfection (Figures $3(\mathrm{~b})$ and $3(\mathrm{c})$ ). The H5N1 viral antigen (NP) was detected extensively in the deciduous alveolar cells and mucosal epithelium cells in the lung (Figure 3(e)). Compared with TN group, more H5N1 viral antigen positive cells could be found in the lung of mice after $\mathrm{CHS}$ treatment. And the results were consistent with the ones of qPCR and plaque assay. 
TN

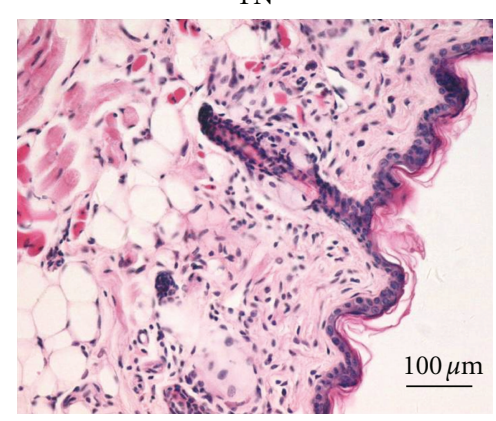

(a)

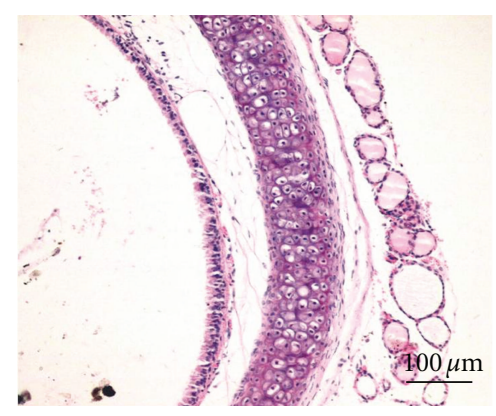

(c)

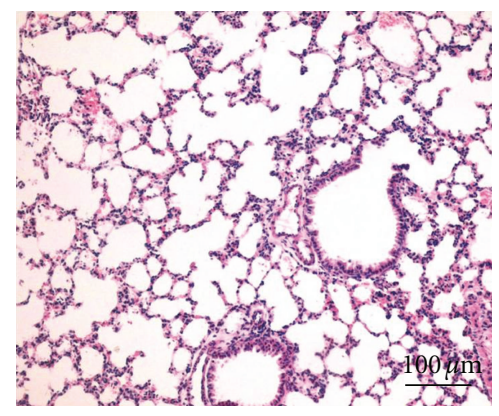

(e)

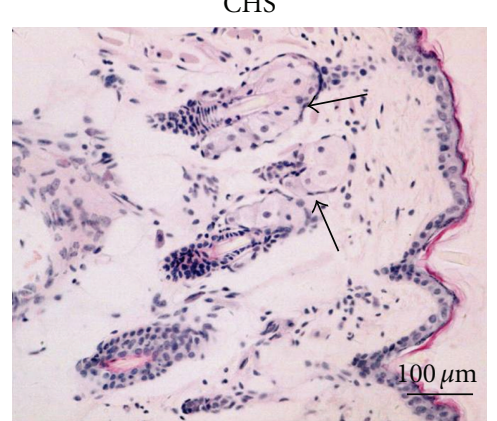

(b)

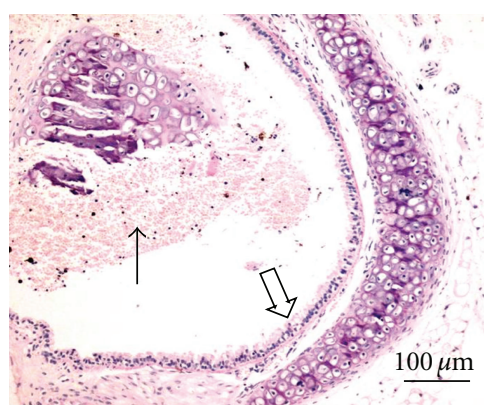

(d)

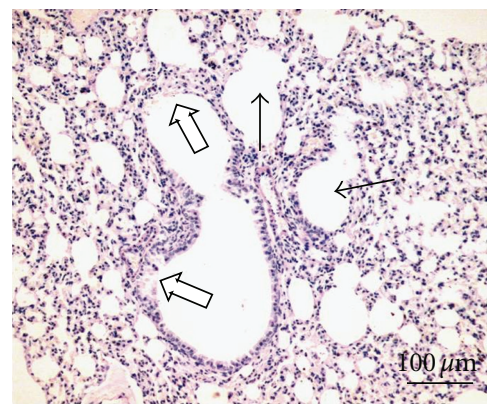

(f)

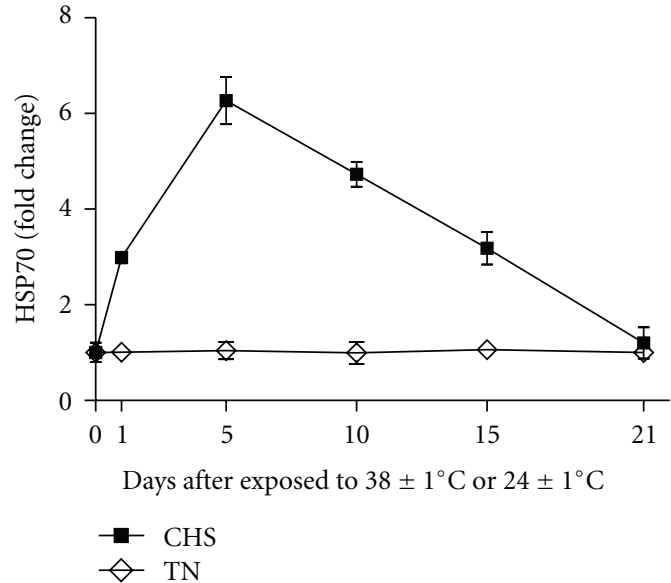

(B)

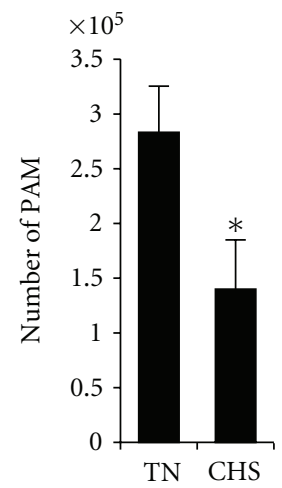

(C)

(A)

Figure 1: Analysis of the local immunity in the respiratory tract of mice. (A) Representative sections from each group were stained by H\&E after exposed to $38 \pm 1^{\circ} \mathrm{C}$ or $24 \pm 1^{\circ} \mathrm{C}$ over 21 days $(400 \times)$. (a) Normal nasal sections from TN mice. (b) Nasal lesions from CHS mice. Solid arrows indicate sebaceous gland hyperplasia. (c) Normal tracheal sections from TN mice. (d) Tracheal lesions from CHS mice. Solid arrows indicate erythrocytes infiltrated in the tube cavity of the trachea and unshaded arrows indicate the dropout of trachea epithelium cells. (e) Normal lung section from TN mice. (f) Lung lesion from CHS mice. Solid arrows indicate alveolar expansion and unshaded arrows indicate a reduction and necrosis of mucous epithelial cells. (B) The mRNA levels of HSP70 in the lungs were determined by qPCR at various time-points. (C) PAM counting from BAL was performed after exposure to $38 \pm 1^{\circ} \mathrm{C}$ or $24 \pm 1^{\circ} \mathrm{C}$ for 21 days. These results are the mean \pm SD values obtained from three distinct animals and are representative of three independent experiments. $*$ indicates $P<.05$ when compared with the TN group. TN: thermally neutral; CHS: chronic heat stress.

The multiple functions of inflammation induced by H5N1 infection potentially affect virus clearance from the host. To evaluate the effect of CHS on inflammation in infected mice, expression of cytokines IL-6, IFN- $\beta$, and IL-10 in the lung was determined by $\mathrm{qPCR}$ at day 3 postinfection. The mRNA levels of IL- 6 and IFN- $\beta$ in the mice of the CHS group were significantly lower than those in the TN group (Figure 3(d)). The soluble cytokine levels in serum of IL6 and IFN- $\beta$ were also measured by ELISA, and the results were in similar trend to the mRNA levels (data not shown). The expression of HSP70 at day 3 postinfection was also determined by qPCR. The results did not show significant differences between two groups (Figure 3(d)). These data indicated that CHS could moderately increase the mortality rate and viral load in the lungs of H5N1-infected mice by decreasing IL- 6 and IFN- $\beta$ expression.

To determine the degree of lung lesion in the infected mice, histopathological changes in the lungs of mice in 

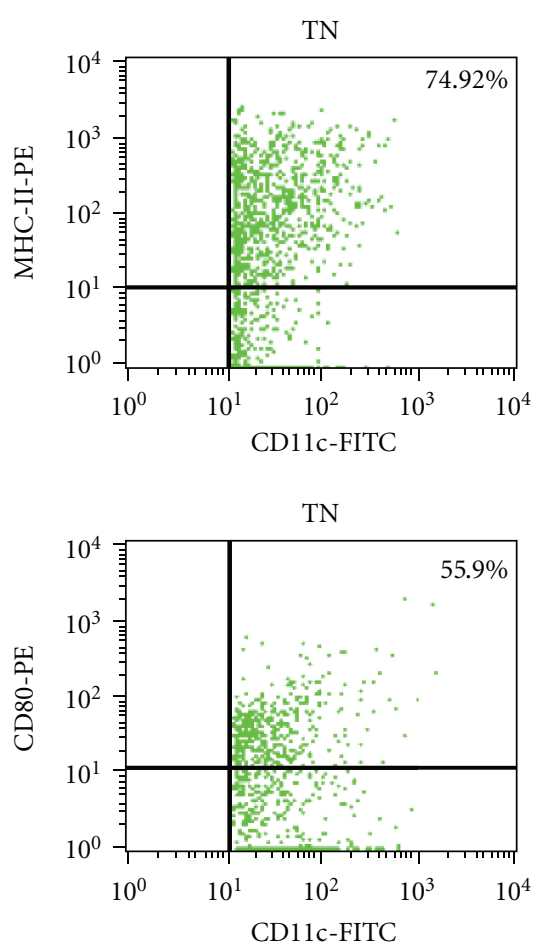

CD11c-FITC
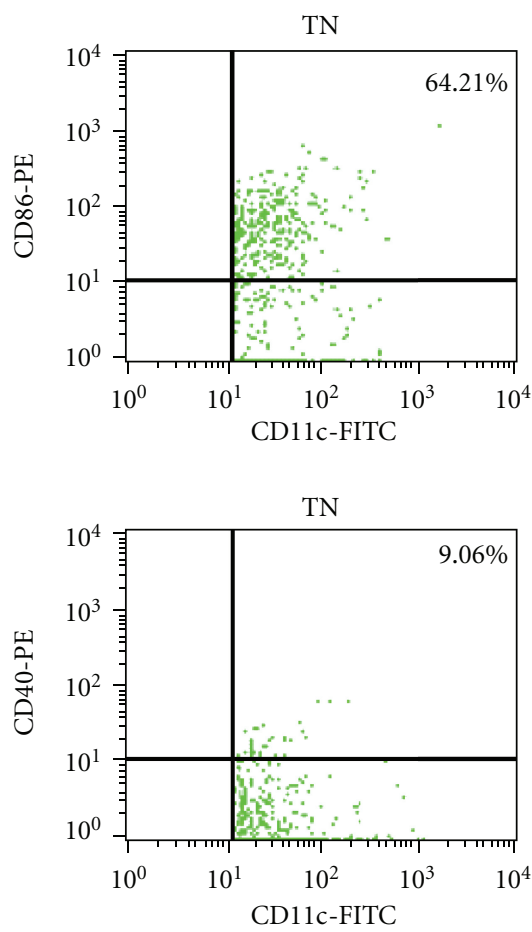

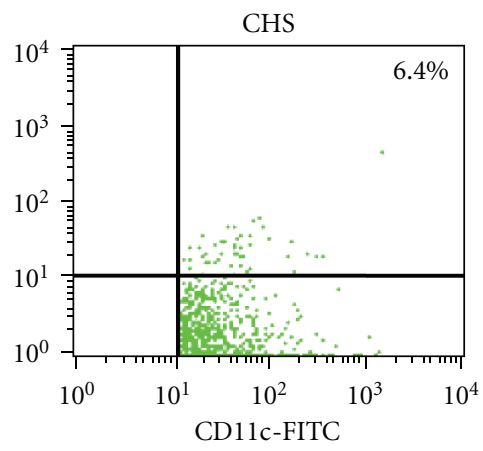

(a)
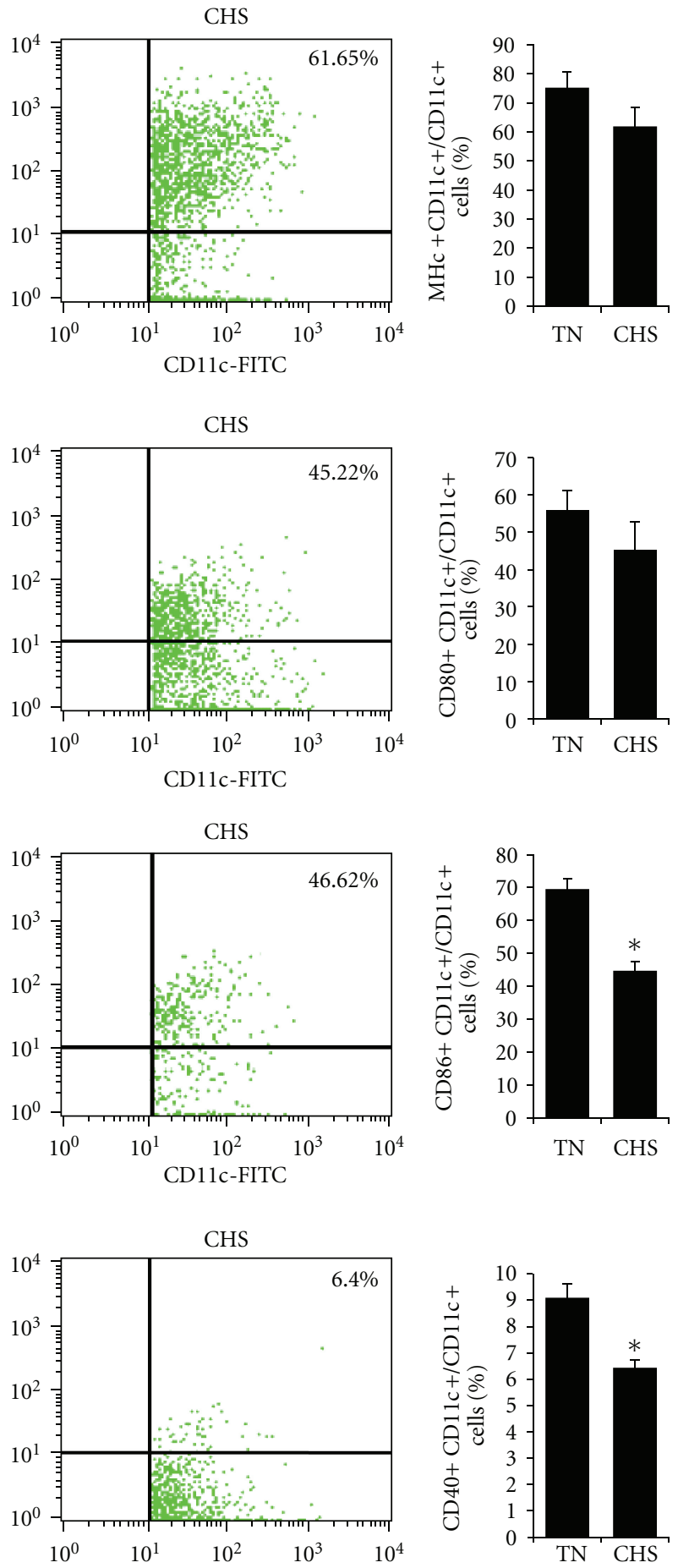

(b)
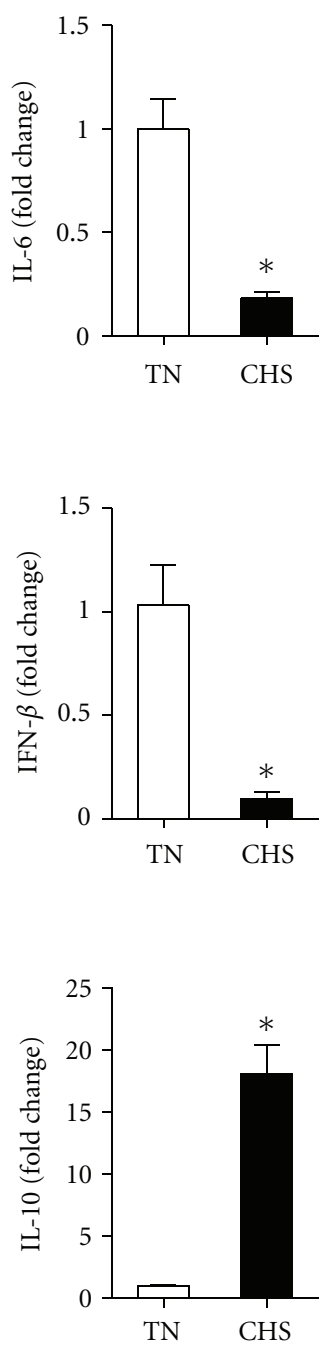

FIGURE 2: Analysis of maturation of DCs and innate immunity associated cytokine expression in mice. (a) Total splenocytes were isolated from the spleen of mice exposed to $38 \pm 1^{\circ} \mathrm{C}$ or $24 \pm 1^{\circ} \mathrm{C}$ over 21 days. Double staining for MHC-II+ CD11c+, CD80+ CD11c+, CD86+ $\mathrm{CD} 11 \mathrm{c}+$, and $\mathrm{CD} 40+\mathrm{CD} 11 \mathrm{c}+$ cells was performed. The proportion of double-positive cells in the dot-plot are shown in the upper right corner of the quadrant, with the gate set for CD11c+ cells or events. Data shown are representative of three independent experiments. (b) Summaries of the proportion of MHC-II+ among total CD11c+ cells, CD80+ among CD11c + cells, CD86+ among CD11c+ cells, and CD40+ among CD11c+ cells. (c) IL-6, IFN- $\beta$, and IL-10 mRNA levels from the spleens of mice exposed to $38 \pm 1^{\circ} \mathrm{C}$ or $24 \pm 1^{\circ} \mathrm{C}$ for 21 days were determined by qPCR. These results are the mean \pm SD values obtained from three distinct animals and are representative of three independent experiments. * indicates $P<.05$ when compared with the TN group. 


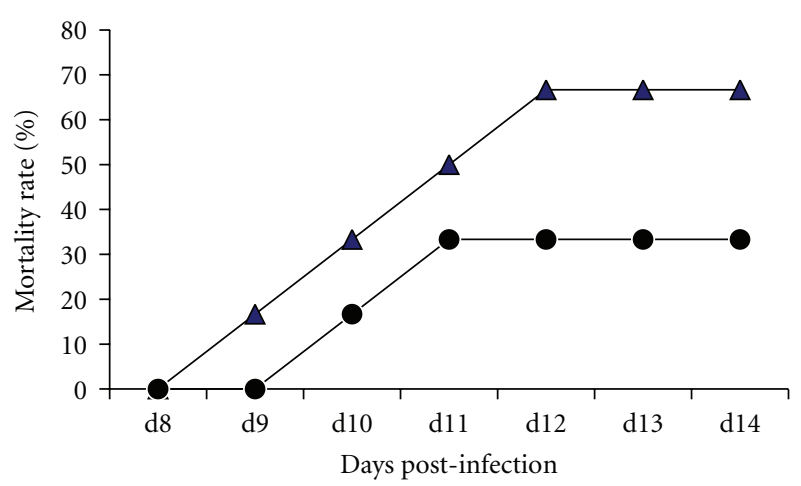

$\triangle \mathrm{CHS}$

(a)

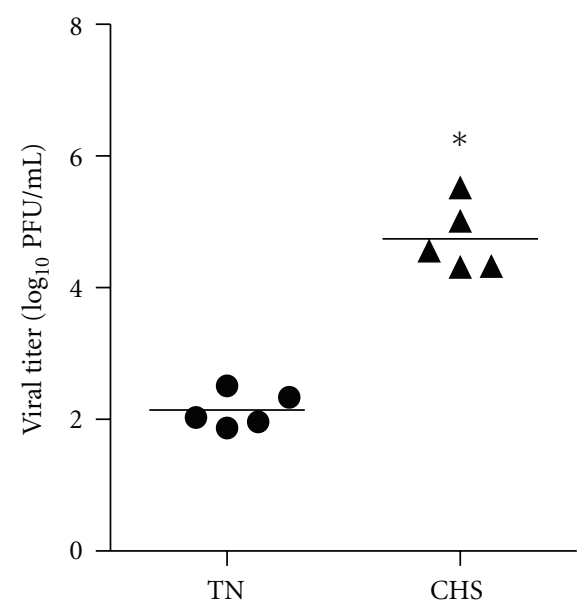

TN

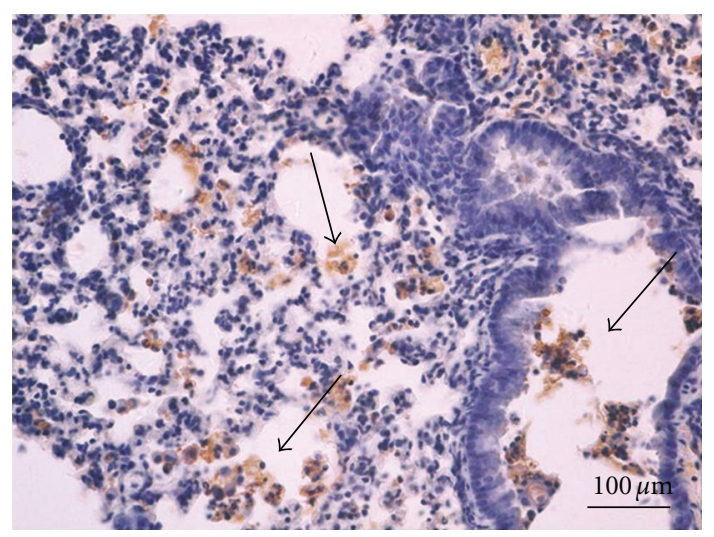

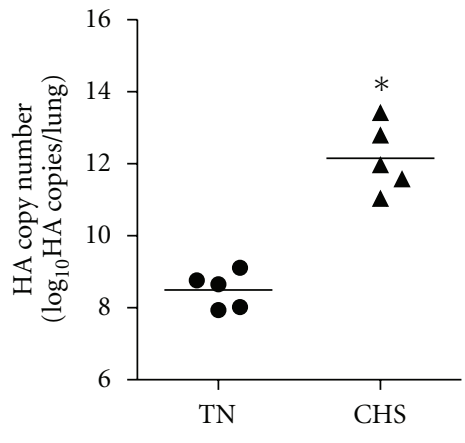

(b)

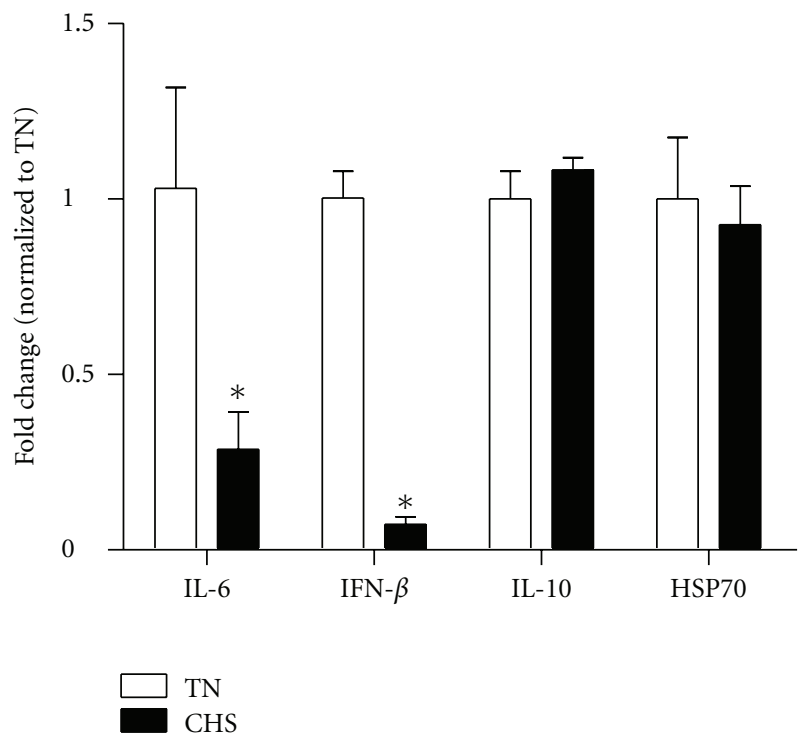

(d)

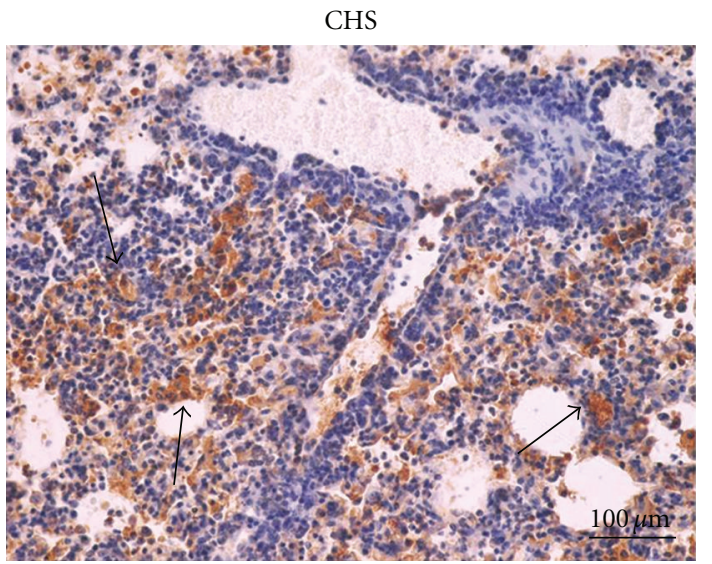

(e)

FIgURE 3: Effects of CHS on the virulence of HPAIV in the infected mice. (a) Six mice per group were observed for mortality at 14 days. And the viral load in lungs at day 3 postinfection was determined by real-time PCR (b) and plaque assay (c). (d) The mRNA levels of IL-6, IFN- $\beta$, IL-10, and HSP70 in the lung at day 3 postinfection were determined by qPCR. * indicates $P<.05$ when compared with the TN group. (e) Representative lung sections from each group were stained with immunohistochemical staining with an antiinfluenza NP mAb (400 $\times)$, and the arrow indicated the NP positive cells. 
each group at day 3 postinfection were examined (Figure 4). The lungs of the CHS group mice showed severe alveolitis, peribronchiolitis, and bronchopneumonia, that was characterized by interstitial edema and inflammatory cellular infiltration around small blood vessels, reduction and necrosis of the mucous epithelium of bronchioles, thickening of alveolar walls, and alveolar lumens flooded with edema fluid mixed with exfoliated alveolar epithelial cells, erythrocytes, and inflammatory cells (Figure 4(c)). The trachea of mice in the CHS group exhibited lesions, characterized by exfoliated trachea mucous epithelium cells and a number of erythrocytes and inflammatory cells infiltrated in the tube cavity of the trachea (Figure $4(\mathrm{~d})$ ). In mice of the TN group, the lung and trachea lesions were dramatically milder than those observed in the CHS group. The lung lesions in the TN group mice showed peribronchiolitis with interstitial edema and inflammatory cell infiltration around small blood vessels, along with edema and reduction of mucous epithelial cells of the bronchioles (Figure 4(a)). The trachea lesions of mice in the TN group mainly demonstrated erythrocyte infiltration (Figure 4(b)). The results suggested that exposure to $38 \pm$ $1^{\circ} \mathrm{C}$ for 21 days aggravated lung and trachea lesions in $\mathrm{H} 5 \mathrm{~N} 1-$ infected mice.

\section{Discussion}

In a previous study, we reported that CHS could retard the adaptive immune response by suppressing both humoral and cellular responses [2]. In this study we have demonstrated that CHS can significantly suppress host innate immunity in mice and moderately increase the mortality of H5N1infected mice. CHS retarded systemic and local innate immune responses significantly, including the number of PAMs, DC maturation, mRNA levels of IL- 6 , IFN- $\beta$, and HSP70, and caused respiratory system lesions. When mice were infected with $\mathrm{H} 5 \mathrm{~N} 1$ virus after $\mathrm{CHS}$ conditioning, the mortality rate and viral load in the lungs increased. Lung histopathology results of infected mice further confirmed that CHS could moderately increase virulence in $\mathrm{H} 5 \mathrm{~N} 1-$ infected mice.

The respiratory mucosa is the first barrier encountered by invading microorganisms. The function and immunity of the respiratory system was closely related to mucosal architecture, PAMs, and other local immune cells or proteins. In the present study, we showed that CHS could reduce local immunity in the respiratory tract of mice by destroying the structural integrity of nasal mucosa, trachea, and lungs and reducing the number of PAMs. The results suggested that CHS could retard the local immunity in respiratory system in mice and rendered them to be susceptible to secondary infection of bacteria or viruses.

Heat stress is often characterized by the production of HSPs. The HSPs, in particular Hsp27, Hsp32, Hsp60, and Hsp70, have an important cytoprotective role during lung inflammation and injury [16], as they can activate the innate immune system, linking innate and adaptive immune responses [21, 22]. Previous studies also indicated that HSPs played an immunoregulatory role in chronic inflammation
$[23,24]$. The results of the expression of HSP70 under chronic heat stress in this study showed that the HSP70 level increased on day 1 , peaked on day 5 , decreased from day 10 , and appeared to be normal level on day 21 after exposure to $38 \pm 1^{\circ} \mathrm{C}$, which suggested that the lack of HSP70 may be associated with the suppression of innate immunity by CHS.

The DCs are the most potent antigen presenting cells (APCs), and activation of DCs is a crucial and early event of immune regulation [25]. The expression of costimulatory molecules (CD40, CD86, and CD80) at the DC surface correlated with their capacity to induce or suppress immune responses. The MHC-II molecules expressed on the surface of APCs are important in the initiation of an immune response [17]. In this study, we observed lower levels of expression of MHC-II, CD40, CD80, and CD86 in CHS mice compared to the TN mice, which indicated that CHS weakened antigen processing not only in APCs but also in the co-stimulatory pathway, which in turn leads to lower immune responses. IL- 6 and IFN- $\beta$ play critical roles in the development and maintenance of innate immune responses $[18,19,26]$. IL-10 has been considered to be a suppressive cytokine known to inhibit Th1 cytokine expression [20, $27,28]$. We have shown that CHS downregulates IL-6 and IFN- $\beta$ expression and upregulates the levels of IL-10. These data further demonstrated that CHS induced lower innate immunity.

The $\mathrm{H} 5 \mathrm{~N} 1$ influenza virus can cause severe respiratory symptoms in humans with clinical manifestations that include fever, diarrhea, viral pneumonia, encephalitis, and acute respiratory distress syndrome. High levels of proinflammatory cytokines, including TNF- $\alpha$, IL-6, and CC chemokine ligand 2 (CCL2), have been detected in human cells and mice infected with highly pathogenic $\mathrm{H} 5 \mathrm{~N} 1$ influenza virus $[29,30]$. Generally, a virus-induced cytokine storm has been widely hypothesized to be the main cause of pathology and death during $\mathrm{H} 5 \mathrm{~N} 1$ infection. There are numerous reports regarding the use of therapeutic agents to control inflammatory responses in influenza infection [31]; however, it is not clear as to whether they are effective in controlling virus replication. Without antiviral agents, knockout mice deficient in TNF- $\alpha$, TNF- $\alpha$ receptor 1 , TNF$\alpha$ receptor 2, IL-6, chemokine (C-C motif) ligand 2, MIP$1 \alpha$, and IL-1R or steroid-treated wild-type mice did not have a survival advantage over wild-type mice following influenza virus challenge $[32,33]$. On the other hand, type I interferon response that contributes to control of H5N1 virus replication has been demonstrated $[34,35]$. The multiple functions of inflammation and cytokines are essential for virus clearance from the host. The antiviral immune response induced by $\mathrm{H} 5 \mathrm{~N} 1$ virus infection was complicated, involving multiple classes of pattern recognition receptors (PRRs), and different signaling pathways. Although the inflammation is widely suggested to be the main cause of death from $\mathrm{H} 5 \mathrm{~N} 1$ infection, the results from the knockout mice deficient in single cytokine were insufficient to clarify the complex process. In this study, our results suggested that CHS treatment retarded the innate immunity. This may be one of the underlying causes of increased death rates by $\mathrm{H} 5 \mathrm{~N} 1$ virus after $\mathrm{CHS}$ treatment. 


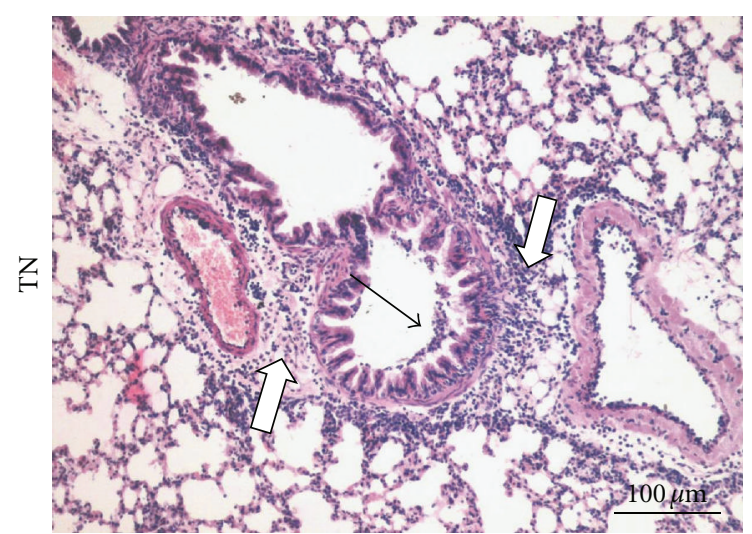

(a)

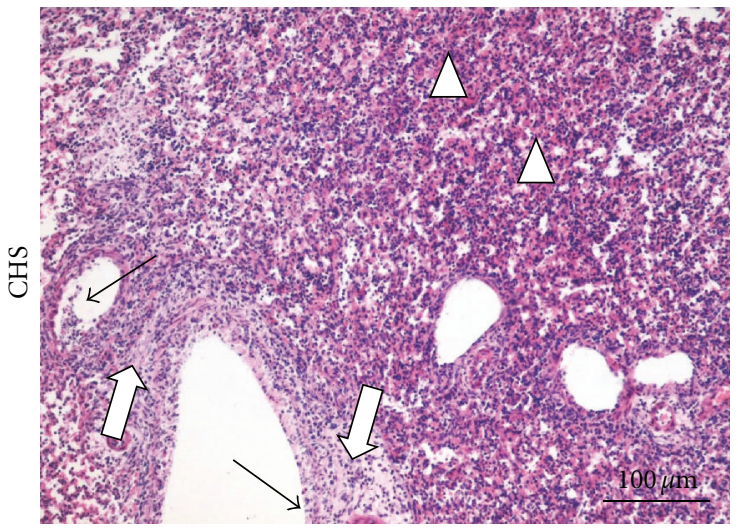

(c)

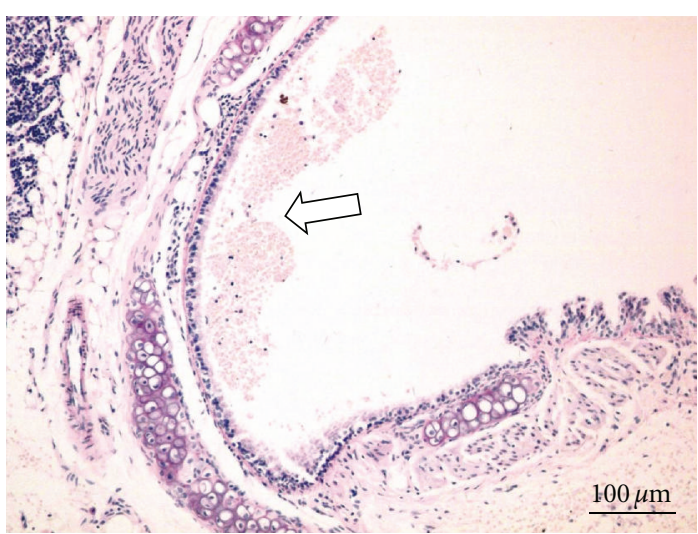

(b)

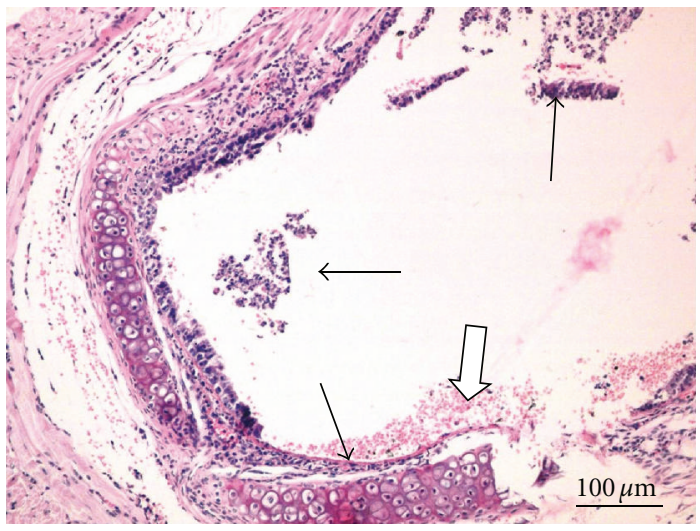

(d)

FIGURE 4: Lung and trachea histopathology following H5N1 infection in mice. Representative lung or trachea sections from each group were stained by H\&E $(400 \times)$. (a) The lung lesions in the TN group of mice showed peribronchiolitis. Solid arrows indicate a reduction in the number of mucous epithelial cells in bronchioles, and unshaded arrows indicate interstitial edema and inflammatory cellular infiltration around small blood vessels and the bronchioles. (b) The tracheal lesions in the TN group of mice. Unshaded arrows indicate erythrocyte infiltration. (c) The lung lesions in the CHS group of mice showed severe alveolitis, peribronchiolitis, and bronchopneumonia. The solid arrows indicate a reduction in necrosis and the number of mucous epithelial cells in bronchioles, with unshaded arrows indicating extreme interstitial edema and vast inflammatory cellular infiltration. Triangles indicate alveolar lumens flooded with edema fluid mixed with exfoliated alveolar epithelial cells, erythrocytes, and inflammatory cells. (d) The tracheal lesions in the CHS group of mice. Solid arrows indicate exfoliation or necrosis of tracheal mucous epithelial cells, and unshaded arrows indicate erythrocytes and inflammatory cellular infiltration in the tube cavity of the trachea.

In summary, the data presented here demonstrate that CHS treatment significantly suppressed innate host immunity in mice and increased mortality following H5N1 infection. This study is the first to show that CHS affects systemic and local innate immune responses as well as survival of H5N1-infected in mice. Our results suggest that after a long period of suffering elevated temperatures, the balance in the immune system is destroyed and $\mathrm{H} 5 \mathrm{~N} 1$ virulence is increased.

\section{Acknowledgments}

The authors thank the National Natural Science Foundation of China (Grant no. 31001047) and the Research Fund for the Doctoral Program of Higher Education (Grant no.
20100008120006) for financial support. Y. Jin and Y. Hu Two contributed to the work equally.

\section{References}

[1] M. S. Goligorsky, "The concept of cellular "fight-or-flight" reaction to stress," American Journal of Physiology, vol. 280, no. 4, pp. F551-F561, 2001.

[2] Y. Hu, H. Jin, X. Du et al., "Effects of chronic heat stress on immune responses of the foot-and-mouth disease DNA vaccination," DNA and Cell Biology, vol. 26, no. 8, pp. 619626, 2007.

[3] M. Khajavi, S. Rahimi, Z. M. Hassan, M. A. Kamali, and T. Mousavi, "Effect of feed restriction early in life on humoral and cellular immunity of two commercial broiler strains under heat stress conditions," British Poultry Science, vol. 44, no. 3, pp. 490-497, 2003. 
[4] L. Le Bellego, J. van Milgen, and J. Noblet, "Effect of high temperature and low-protein diets on the performance of growing-finishing pigs," Journal of Animal Science, vol. 80, no. 3, pp. 691-701, 2002.

[5] Q. Lu, J. Wen, and H. Zhang, "Effect of chronic heat exposure on fat deposition and meat quality in two genetic types of chicken," Poultry Science, vol. 86, no. 6, pp. 1059-1064, 2007.

[6] N. E. Odongo, O. Alzahal, M. I. Lindinger et al., "Effects of mild heat stress and grain challenge on acid-base balance and rumen tissue histology in lambs," Journal of Animal Science, vol. 84, no. 2, pp. 447-455, 2006.

[7] P. K. Liew, I. Zulkifli, M. Hair-Bejo, A. R. Omar, and D. A. Israf, "Effects of early age feed restriction and heat conditioning on heat shock protein 70 expression, resistance to infectious bursal disease, and growth in male broiler chickens subjected to heat stress," Poultry Science, vol. 82, no. 12, pp. 1879-1885, 2003.

[8] I. Zulkifli, N. Abdulllah, N. M. Azrin, and Y. W. Ho, "Growth performance and immune response of two commercial broiler strains fed diets containing Lactobacillus cultures and oxytetracycline under heat stress conditions," British Poultry Science, vol. 41, no. 5, pp. 593-597, 2000.

[9] T. F. Davison, B. H. Misson, R. A. Williamson, and J. Rea, "Effect of increased circulating corticosterone in the immature fowl on the blastogenic responses of peripheral blood lymphocytes," Developmental and Comparative Immunology, vol. 12, no. 1, pp. 131-144, 1988.

[10] R. A. Donker and G. Beuving, "Effect of corticosterone infusion on plasma corticosterone concentration, antibody production, circulating leukocytes and growth in chicken lines selected for humoral immune responsiveness," British Poultry Science, vol. 30, no. 2, pp. 361-369, 1989.

[11] L. Q. Fang, S. J. de Vlas, S. Liang et al., "Environmental factors contributing to the spread of $\mathrm{H} 5 \mathrm{~N} 1$ avian influenza in mainland China," PLoS One, vol. 3, no. 5, Article ID e2268, 2008.

[12] L. Q. Fang, C. X. Cao, G. S. Chen et al., "Studies on the spatial distribution and environmental factors of highly pathogenic avian influenza in Mainland China, using geographic information system technology," Chinese Journal of Epidemiology, vol. 26, no. 11, pp. 839-842, 2005 (Chinese).

[13] Y. Wu, G. Zhang, Y. Li et al., "Inhibition of highly pathogenic avian $\mathrm{H} 5 \mathrm{~N} 1$ influenza virus replication by RNA oligonucleotides targeting NS1 gene," Biochemical and Biophysical Research Communications, vol. 365, no. 2, pp. 369-374, 2008.

[14] R. K. Sinha, "Electro-encephalogram disturbances in different sleep-wake states following exposure to high environmental heat," Medical and Biological Engineering and Computing, vol. 42, no. 3, pp. 282-287, 2004.

[15] K. J. Livak and T. D. Schmittgen, "Analysis of relative gene expression data using real-time quantitative PCR and the 2(Delta Delta C(T)) method," Methods, vol. 25, no. 4, pp. 402408, 2001.

[16] D. S. Wheeler and H. R. Wong, "Heat shock response and acute lung injury," Free Radical Biology and Medicine, vol. 42, no. 1, pp. 1-14, 2007.

[17] A. Clatza, L. C. Bonifaz, D. A. Vignali, and J. Moreno, "CD40-induced aggregation of MHC class II and CD80 on the cell surface leads to an early enhancement in antigen presentation," Journal of Immunology, vol. 171, no. 12, pp. 6478-6487, 2003.

[18] T. B. Thornley, N. E. Phillips, B. C. Beaudette-Zlatanova et al.,
"Type 1 IFN mediates cross-talk between innate and adaptive immunity that abrogates transplantation tolerance," Journal of Immunology, vol. 179, no. 10, pp. 6620-6629, 2007.

[19] T. J. Vanden Bush, C. M. Buchta, J. Claudio, and G. A. Bishop, "Cutting edge: importance of IL-6 and cooperation between innate and adaptive immune receptors in cellular vaccination with B lymphocytes," Journal of Immunology, vol. 183, no. 8, pp. 4833-4837, 2009.

[20] K. Nakagome, M. Dohi, K. Okunishi et al., "In vivo IL-10 gene delivery suppresses airway eosinophilia and hyperreactivity by down-regulating APC functions and migration without impairing the antigen-specific systemic immune response in a mouse model of allergic airway inflammation," Journal of Immunology, vol. 174, no. 11, pp. 6955-6966, 2005.

[21] K. M. Anderson and P. K. Srivastava, "Heat, heat shock, heat shock proteins and death: a central link in innate and adaptive immune responses," Immunology Letters, vol. 74, no. 1, pp. 3539, 2000.

[22] R. P. Wallin, A. Lundqvist, S. H. More, A. von Bonin, R. Kiessling, and H. G. Ljunggren, "Heat-shock proteins as activators of the innate immune system," Trends in Immunology, vol. 23, no. 3, pp. 130-135, 2002.

[23] E. Hirayama, "Relationship of HSP70 to temperaturedependency of influenza viral infection," Yakugaku Zasshi, vol. 124, no. 7, pp. 437-442, 2004.

[24] W. Van Eden, G. Wick, S. Albani, and I. Cohen, "Stress, heat shock proteins, and autoimmunity: how immune responses to heat shock proteins are to be used for the control of chronic inflammatory diseases," Annals of the New York Academy of Sciences, vol. 1113, pp. 217-237, 2007.

[25] B. J. Weigel, N. Nath, P. A. Taylor et al., "Comparative analysis of murine marrow-derived dendritic cells generated by Flt3L or GM-CSF/IL-4 and matured with immune stimulatory agents on the in vivo induction of antileukemia responses," Blood, vol. 100, no. 12, pp. 4169-4176, 2002.

[26] K. Popko, E. Gorska, A. Stelmaszczyk-Emmel et al., "Proinflammatory cytokines Il-6 and TNF-alpha and the development of inflammation in obese subjects," European Journal of Medical Research, vol. 15, 2, pp. 120-122, 2010.

[27] Z. Yang, M. Chen, R. Wu et al., "Suppression of autoimmune diabetes by viral IL-10 gene transfer," Journal of Immunology, vol. 168, no. 12, pp. 6479-6485, 2002.

[28] D. F. Fiorentino, A. Zlotnik, P. Vieira et al., "IL-10 acts on the antigen-presenting cell to inhibit cytokine production by Th1 cells," Journal of Immunology, vol. 146, no. 10, pp. 3444-3451, 1991.

[29] K. J. Szretter, S. Gangappa, X. Lu et al., "Role of host cytokine responses in the pathogenesis of avian $\mathrm{H} 5 \mathrm{~N} 1$ influenza viruses in mice," Journal of Virology, vol. 81, no. 6, pp. 2736-2744, 2007.

[30] M. C. Chan, C. Y. Cheung, W. H. Chui et al., "Proinflammatory cytokine responses induced by influenza A (H5N1) viruses in primary human alveolar and bronchial epithelial cells," Respiratory Research, vol. 6, Article ID 135, 2005.

[31] K. D. Rainsford, "Influenza ("Bird Flu”), inflammation and anti-inflammatory/analgesic drugs," Inflammopharmacology, vol. 14, no. 1-2, pp. 2-9, 2006.

[32] R. Salomon, E. Hoffmann, and R. G. Webster, "Inhibition of the cytokine response does not protect against lethal H5N1 influenza infection," Proceedings of the National Academy of Sciences of the United States of America, vol. 104, no. 30, pp. 12479-12481, 2007. 
[33] M. J. Carter, "A rationale for using steroids in the treatment of severe cases of H5N1 avian influenza," Journal of Medical Microbiology, vol. 56, no. 7, pp. 875-883, 2007.

[34] K. J. Szretter, S. Gangappa, J. A. Belser et al., "Early control of H5N1 influenza virus replication by the type I interferon response in mice," Journal of Virology, vol. 83, no. 11, pp. 58255834, 2009.

[35] E. Haasbach, K. Droebner, A. B. Vogel, and O. Planz, "LowDose Interferon Type I Treatment Is Effective Against H5N1 and Swine-Origin H1N1 Influenza a Viruses In vitro and In vivo," Journal of Interferon and Cytokine Research. In Press. 


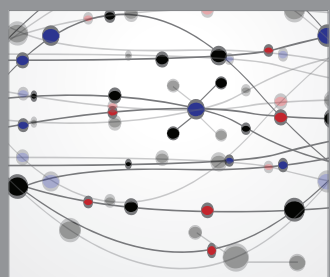

The Scientific World Journal
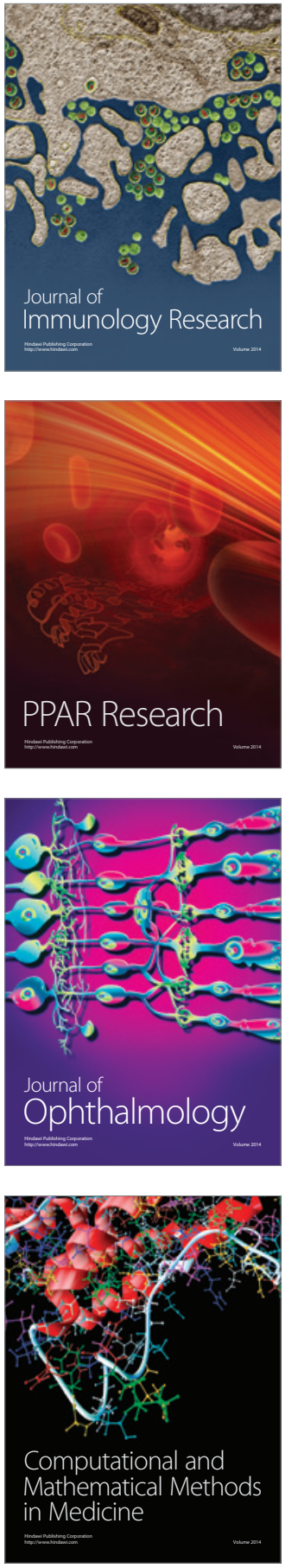

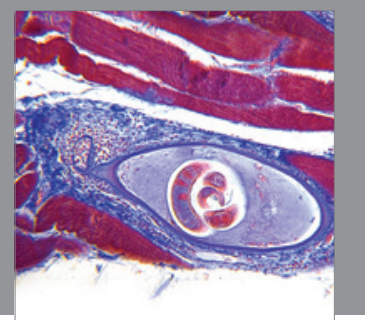

Gastroenterology

Research and Practice
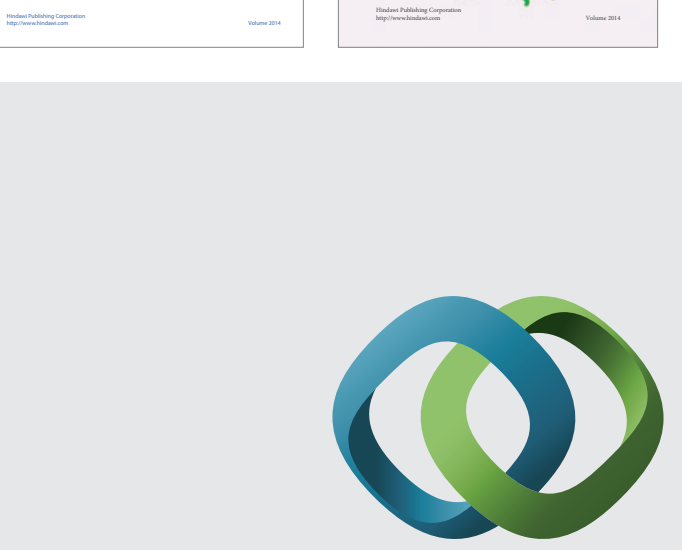

\section{Hindawi}

Submit your manuscripts at

http://www.hindawi.com
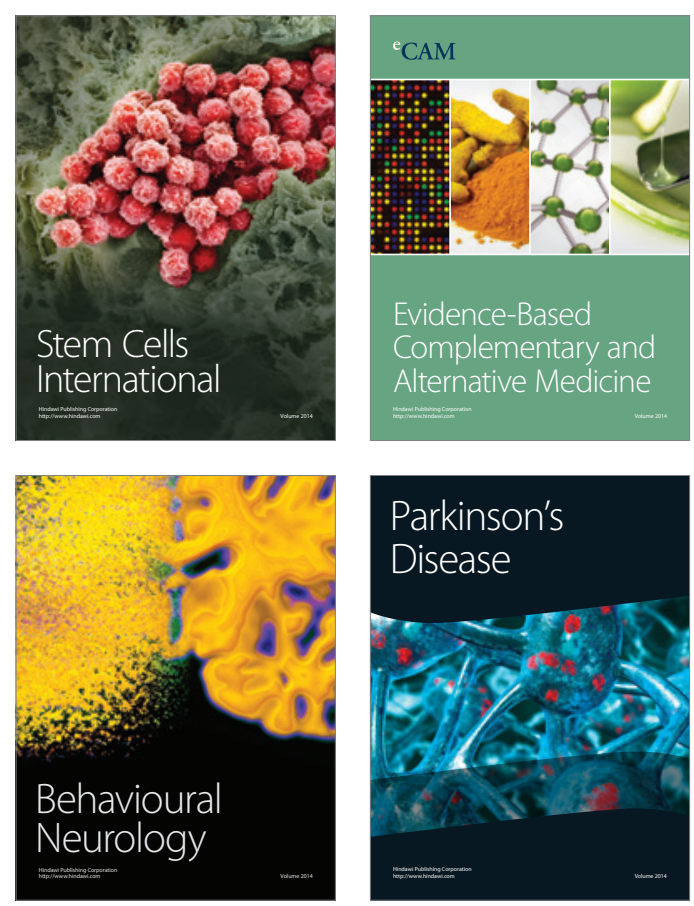

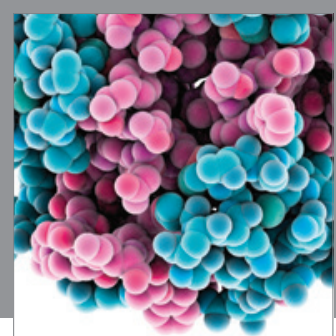

Journal of
Diabetes Research

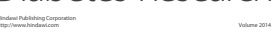

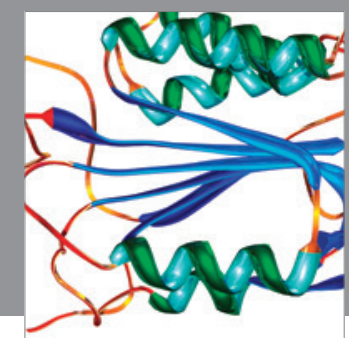

Disease Markers
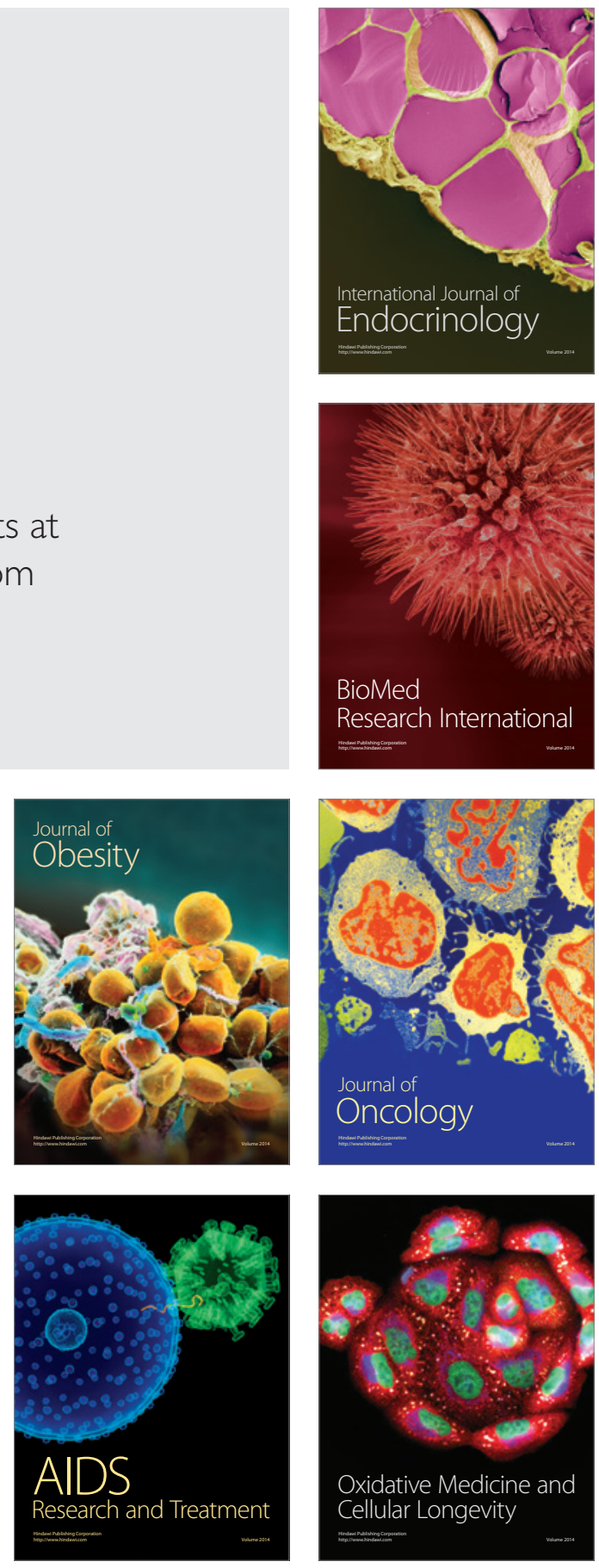